\title{
Genetic, cytogenetic and physical refinement of the autosomal recessive CMT linked to 5q31-q33: exclusion of candidate genes including EGR1
}

\author{
Angèle Guilbot ${ }^{1}$, Nicole Ravisé ${ }^{1}$, Ahmed Bouhouche ${ }^{6}$, Philippe Coullin ${ }^{4}$, \\ Nazha Birouk ${ }^{6}$, Thierry Maisonobe ${ }^{3}$, Thierry Kuntzer ${ }^{7},{\text { Christophe } \text { Vial }^{8} \text {, Djamel Grid }}^{5}$, \\ Alexis Brice ${ }^{1,2}$ and Eric LeGuern ${ }^{1,2}$ \\ ${ }^{1}$ INSERM U289, ${ }^{2}$ Fédération de Neurologie and ${ }^{3}$ Laboratoire de Neuropathologie $R$ Escourolle, Hôpital de la \\ Salpêtrière, Paris \\ ${ }^{4}$ Laboratoire de cytogénétique, Villejuif \\ ${ }^{5}$ Généthon, Evry, France \\ ${ }^{6}$ Service de Neurologie, Hôpital des Spécialités, Rabat, Morocco \\ ${ }^{7}$ Service de Neurologie, Centre Hospitalier Universitaire Vaudois, Lausanne, Switzerland \\ ${ }^{8}$ Service D'EMG et de pathologie neuromusculaire, Hôpital neurologique Pierre Wertheimer, Lyon, France
}

\begin{abstract}
Charcot-Marie-Tooth disease is an heterogeneous group of inherited peripheral motor and sensory neuropathies with several modes of inheritance: autosomal dominant, $X$-linked and autosomal recessive. By homozygosity mapping, we have identified, in the 5q23-q33 region, a third locus responsible for an autosomal recessive form of demyelinating CMT. Haplotype reconstruction and determination of the minimal region of homozygosity restricted the candidate region to a $4 \mathrm{cM}$ interval. A physical map of the candidate region was established by screening YACs for microsatellites used for genetic analysis. Combined genetic, cytogenetic and physical mapping restricted the locus to a less than $2 \mathrm{Mb}$ interval on chromosome $5 \mathrm{q32}$. Seventeen consanguineous families with demyelinating ARCMT of various origins were screened for linkage to 5q31-q33. Three of these seventeen families are probably linked to this locus, indicating that the $5 q$ locus accounts for about $20 \%$ of demyelinating ARCMT. Several candidate genes in the region were excluded by their position on the contig and/or by sequence analysis. The most obvious candidate gene, EGR1, expressed specifically in Schwann cells, mapped outside of the candidate region and no base changes were detected in two families by sequencing of the entire coding sequence.
\end{abstract}

Keywords: Charcot-Marie-Tooth disease; autosomal recessive form; 5 q32 physical mapping; EGR1 gene; $C D X 1$ gene

Correspondence: Angèle Guilbot, INSERM U289, Hôpital de la Salpêtrière, 47 Bvd de l'Hôpital, 75651 Paris cedex 13, France. Tel: 00331421621 82; Fax: 0033144243658 ; E-mail: guilbot@ccr.jussieu.fr

Received 22 March 1999; revised 25 May 1999; accepted 10

June 1999 


\section{Introduction}

Charcot-Marie-Tooth disease is an heterogeneous group of inherited peripheral motor and sensory neuropathies, characterised by chronic distal weakness with progressive muscular atrophy and sensory loss in the distal extremities. Autosomal dominant, X-linked and autosomal recessive modes of inheritance have been described. Autosomal recessive forms of CMT disease (ARCMT) are classified on the basis of electrophysiological and pathological features ${ }^{1,2}$ but recent results of genetic mapping add a new degree of complexity. So far, four different loci have already been reported: CMT4A in 8q13-q21.1, ${ }^{1,3}$ CMT4B in 11q23, ${ }^{4}$ a locus in 5q23-q33 $3^{5}$ and in 8q24 hereditary motor and sensory neuropathy-Lom (HMSNL) ${ }^{6}$ but none of the corresponding genes have been identified. In a previous study, we localised the 5q23-q33 locus to a $4 \mathrm{cM}$ interval by homozygosity mapping in two consanguineous Algerian families. ${ }^{5}$ In order to identify the corresponding gene, we have now constructed a detailed physical map of this region. Combined genetic, cytogenetic and physical mapping refined the position of this locus to an approximate $2 \mathrm{Mb}$ interval on $5 \mathrm{q} 32$. We also performed linkage analysis of 17 additional consanguineous families of various origin with demyelinating ARCMT. Three of these families are probably linked to the 5q23-q33 region, indicating that this locus represents about 15 to $20 \%$ of the demyelinating ARCMT. We have excluded several candidate genes in the region by their position on the YAC contig and/or by sequence analysis, including EGR1 and $C D X 1$ which, because of their functions, appeared to be excellent candidates.

\section{Materials and Methods}

\section{Physical Mapping}

Total DNA was extracted by standard protocols from 18 YACs previously mapped to chromosome $5 \mathrm{q} 31-\mathrm{q} 33^{7}$ and from 42 additional YACs, selected according to data from the CEPH library. ${ }^{8}$ We first screened YACs with seven sequencetagged sites (STS) derived from Li et al: ${ }^{7}$ D5S70, D5S545, D5S546, D5S547, D5S68, D5S549 and D5S686. In a second step, the YACs were analysed, by PCR, with 17 microsatellite markers (D5S622, D5S642, D5S666, D5S393, D5S658, D5S643, D5S436, D5S402, D5S638, D5S413, D5S434, D5S636, D5S673, D5S410, D5S670, D5S412 and D5S422) from the Généthon map, which were previously used for genetic analysis, ${ }^{5,9}$ and with two additional STS (D5S1702 and D5S1481) from the Whitehead Institute for Biomedical Research database.

\section{FISH Analysis of YACs}

In order to map the YAC contig to the $5 \mathrm{q}$ region and confirm the absence of chimerism, 5 YACs (812E8, 959E5, 841D10,
951A10 and 939F12) were analysed by simultaneous fluorescent in situ hybridisation (FISH) and R-banding by primed in situ labelling (PRINS) according to Coullin et al (personal communication, 1998). Slides were prepared using standard cytogenetic methods. PRINS was performed as previously described, ${ }^{10}$ except that the Alu $\mathrm{S}$ sequence was used as the primer and digoxigenin-11-dUTP as the labelled nucleotide. After PRINS labelling, FISH was performed as described elsewhere, ${ }^{11}$ with PCR amplifid/biotin labelled human YAC inserts as probes. The Alu S and Alu R primer sequences used to amplify human YAC inserts are 5' GCCACTGCACTCCAGCCTGGG 3' and 5' GCCTCCAAAGTGCTGGGATTACAG 3', respectively. ${ }^{12}$ The R-banding pattern provided by Alu-PRINS and the FISH signals were revealed, respectively, by anti-digoxigenin-rhodamine and avidin-FITC, observed by epifluorescence microscopy (Zeiss Axiophot, Thornwood, NY, USA).

\section{Family Screening}

Consanguineous families from Europe and North Africa with ARCMT were collected thanks to a collaborative network of neurologists. The inclusion criteria were: (i) autosomal recessive mode of inheritance, ie at least one affected in a single generation born from related parents who were clinically and electrophysiologically non affected, and (ii) reduced motor nerve conduction velocity in the medium nerve $(\mathrm{MNCV}<48 \mathrm{~m} / \mathrm{s})$ in patients and/or demyelinating neuropathy on nerve biopsy. There were 17 families: six from France (FAR-025, KET-037, CHI-104, MOU-171, CER-295, GOU-1021), four from Saudi Arabia (ALS-332, SAI-336, AIT-337 and BAS-551), three from Morocco (GHA-018, AIT-087 and MAR-576), two from Tunisia (TER-162, RE-531) and two from Portugal (EST-221 and MAN-265). Appropriate informed consents were obtained from available family members (parents, affected and non-affected children) who were genotyped with two co-localised fluorescent markers from the 5q region (D5S643 and D5S436) on an ABI 377 sequencer. Data were analysed by the Genescan ${ }^{\circledR}$ (v3.1) and Genotype ( ${ }^{\circledR}$ (v1.1.1) softwares (PE Applied Biosystems, Foster City, CA, USA). HOMOG analyses ${ }^{13}$ was based on the results of bipoint lod scores, considering haplotypes for markers D5S643/D5S436. The frequencies of each haplotype, ranging from 0.02 to 0.05 , were determined by the observation of the transmitted alleles at each loci in the 17 families. Families with a high posterior probability in favour of linkage were genotyped for 10 additional microsatellite markers spanning the ARCMT locus in 5q31-q33: cen-D5S3931.2 cM-D5666-1.7 cM-D5S207-0.1 cM-D5S658-4.4 cMD5S402-0 cM-116YC5-0 cM-D5S210-0 cM-D5S638-3 cMD5S413-2.2 cM-D5S434. Haplotypes were reconstructed manually and linkage analysis was performed with the LINKAGE and FASTLINK software packages. ${ }^{14,15}$

\section{Gene Mapping}

According to the cDNA sequence of the 15 candidate genes, primers were designed to amplify specific fragments from genomic DNA (see Table 3). Moreover, intragenic polymorphic GT repeats in the $F B N 2^{16}$ and $F G F A$ genes ${ }^{17}$ were tested in patients from families BOU-001 and ABD-210 previously referred to as ALG-BOU and ALG-ABD. ${ }^{5}$ For each experiment, human genomic DNA and ultra-pure water served as positive and negative controls, respectively. 


\section{Sequencing of EGR1 and CDX1 Genes}

Each exon of the EGR1 and $C D X 1$ gene was amplified by PCR in five individuals of family BOU-001 (the two parents, one unaffected child and two patients) and in three members of family ABD-210 (the mother and two patients), using primers designed from the cDNA sequence and according to the determination of the exon/intron structure. ${ }^{18,19}$ The PCR products were sequenced with Bidgye ${ }^{\mathrm{TM}}$ dRhodamine Terminators ${ }^{\circledR}$ (PE Applied Biosystems) on an ABI 377 sequencer and sequence chromatograms were analysed using Autoassembler ${ }^{\circledR}$ software (version 1.4.0, PE Applied Biosystems).

\section{Results}

\section{Physical and Cytogenetic Mapping}

Homozygosity mapping in family BOU-001 which allowed the gene in 5q23-q33 to be localised, led us to identify the $4 \mathrm{cM}$ homozygosity region encompassing the microsatellite markers D5S643 and D5S436 as the candidate interval. We first localised D5S643 and D5S436 on a previously constituted YACs contig of the 5q31-q33 region established with non polymorphic STSs. ${ }^{7}$ Then, we verified the position of STSs in the interval between D5S70 and D5S686. Most results were confirmed, but discrepancies were observed for D5S545 and D5S686. They were previously assigned to YACs 124F11 and 939F12, respectively, but we did not observe amplification products with both of them. In order physically to map the candidate region, the 18 YACs from this contig and 42 additional YACs, previously assigned by CEPH in 5q23-q33, ${ }^{8}$ were tested with the 17 microsatellites markers used for the previous genetic mapping. ${ }^{5}$ Twenty-three YACs belonging to the CEPH library (9 from Li et $\mathrm{l}^{7}$ and 14 from our screening) were selected according to (i) their content of appropriate markers, and (ii) the absence of internal deletions. By combining the results of STSs and polymorphic markers, we constituted a contig ranging from D5S207 to D5S434 with only one gap situated between markers D5S545 and D5S658 (Figure 1). Two

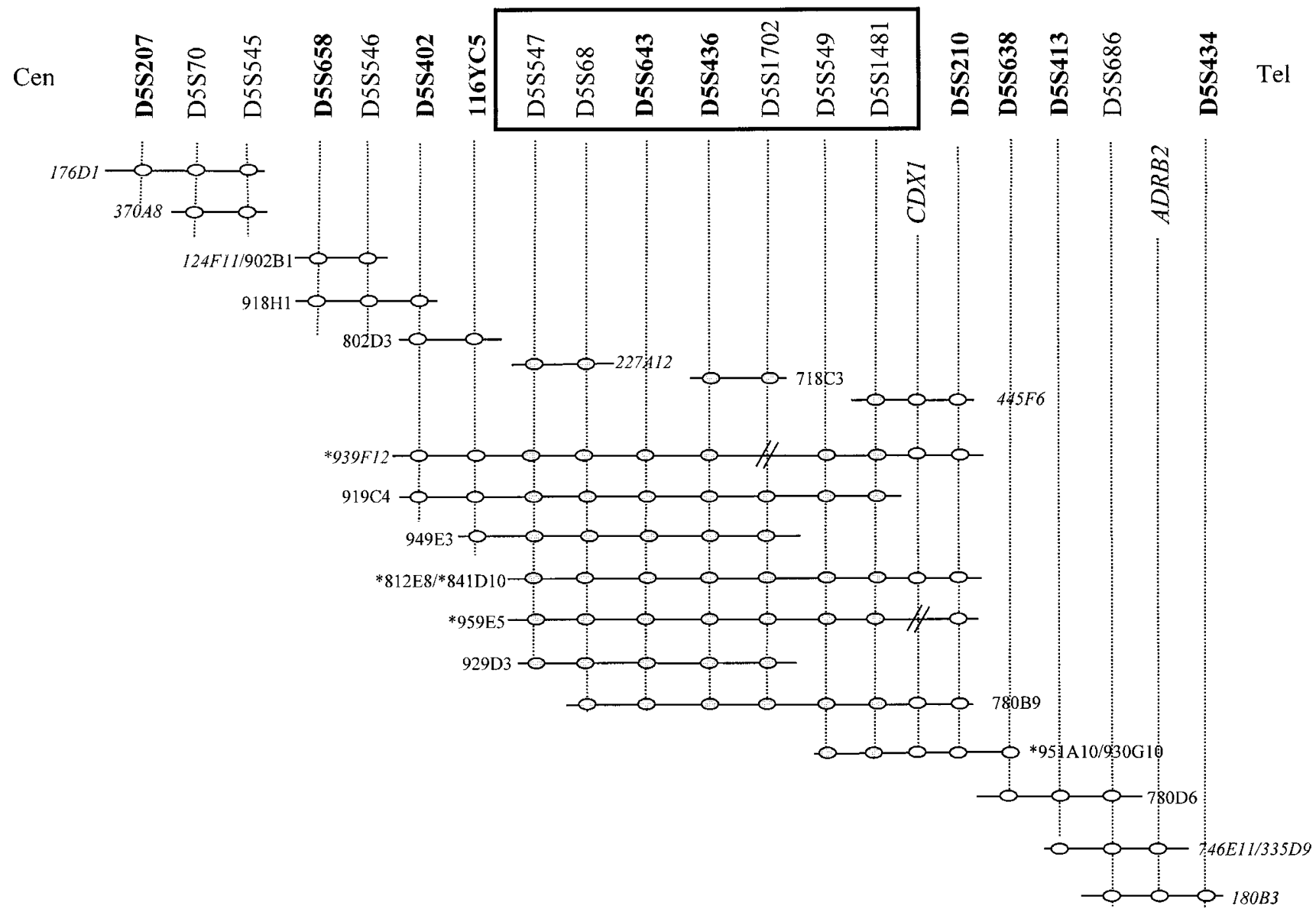

Figure 1 YAC contig from the 5q31-q33 region. Microsatellite markers are in bold. The markers included in the homozygosity region are boxed and their location on the corresponding YACs are shaded. The YACs from Li et al ${ }^{7}$ are in italics. Asterisks indicate the YACs analysed by FISH and absence of amplification is indicated by//. Both genes caudal type homeobox 1 (CDX1) and adrenergic $\beta^{2}$ receptor (ADRB2) were mapped on this contig 
STSs from the Whitehead Institute (D5S1481 and D5S1702) did not allow the gap to be resolved but showed the absence of D5S1702 on YAC939F12, suggesting an internal deletion. In addition, position of marker D5S402, previously located between D5S643 and D5S436 and D5S638 by haplotype reconstruction, was modified because it turned out to be centromeric to D5S643 but telomeric to D5S658 on the YAC contig. Furthermore, we were able to order the microsatellites D5S643 and D5S436 which were co-localised on the Généthon map (D5S436 is telomeric to D5S643) and three new microsatellite markers (D5S207, D5S210 and 116 YC5) were precisely mapped in the contig. A new order of microsatellites in 5q31-q33 can be proposed: cen-D5S393-D5S207-D5S658-D5S402-

116YC5-D5S643-D5S436-D5S210-D5S638-tel.

Three new markers D5S207, D5S210 and 116YC5, were genotyped in families BOU-001 and ABD-210. 116YC5 and D5S210 represented, respectively, the centromeric and telomeric boundaries of the homozygosity region in family BOU-001 (see Figure 3 ). This region was completely included in YAC 939F12 $(1.6 \mathrm{Mb})$ from the contig of Li et al. ${ }^{7}$ In the new contig, 12 overlapping YACs 227A12 (0.45 Mb), $718 \mathrm{C} 3$ $(0.29 \mathrm{Mb}), 445 \mathrm{~F} 6(0.35 \mathrm{Mb}), 919 \mathrm{C} 4(1.5 \mathrm{Mb}), 949 \mathrm{E} 3$ (1.58 Mb), 812E8 (1.44 Mb), 841D10 (1.43 Mb), 959E5 (1.6 Mb), 929D3 (1.72 Mb), 780B9 (0.82 Mb), 951A10 $(0.59 \mathrm{Mb})$ and $930 \mathrm{G} 10(1.52 \mathrm{Mb})$ covered the candidate interval which probably corresponds to a physical distance of less than $2 \mathrm{Mb}$.

FISH analysis combined with Alu-PRINS banding demonstrated the absence of chimerism for four of the five analysed YACs (812E8, 959E5, 841D10 and 951A10) and refined their location in the $5 q 32$ band. YAC 939F12 hybridised specifically with chromosome 3 and 5 , and is therefore chimeric.

\section{Linkage Analysis}

Seventeen consanguineous families (Figure 2) were studied for their linkage to the 5q31-q33 region. They were first tested with the two closest markers flanking the 5q locus: D5S643 and D5S436. ${ }^{5}$ Two-point lod scores for the haplotype D5S643/D5S436 at a recombination fraction $(\Theta)$ of 0.00 were positive (range 0.79-1.77) in families GHA-018 (Morocco), TER-162 (Tunisia) and GOU-1021 (France). They were null or negative for the 14 other families (Table 1). In family GHA-018, a lod score above 1.7 highly supported a linkage. ${ }^{13}$ The lod scores of families TER-162 and GOU-1021 were only slightly positive due to their small size. The odds, calculated with the HOMOG program, in favour of linkage with heterogeneity $(\mathrm{H} 2)$ as opposed to no linkage $(\mathrm{H} 0)$ and to linkage and homogeneity (H1) were $9.53 \times 10^{8}: 1$ and $2.13 \times 10^{4}: 1$, respectively. Haplotypes were reconstructed for 12 microsatellite markers spanning $15.6 \mathrm{cM}$ on chromosome 5 in the three families presenting a high posterior probability (0.67-0.95) of linkage to the ARCMT locus on chromosome 5q31-q33 using the HOMOG program (Figure 3). As in families BOU-001 and ABD-210 with previously demonstrated linkage, ${ }^{5}$ all patients were homozygous for both microsatellite markers D5S643 and D5S436 but the region of homozygosity extended into the flanking regions in the three new families. In family GOU-1021, where the parents are first cousins, the homozygosity region in patient 001 was smaller than expected, but probably larger than $4.4 \mathrm{cM}$ since recombination values from the Généthon map were evaluated from only a limited number of meiosis. A recombination event was observed in family GHA-018 with marker D5S393 in patient 011 which represents the centromeric boundary of the candidate region in this kindred. This recombination event permitted us to place D5S666 telomeric to D5S393. No particular alleles segregated with ARCMT in the five families (data not shown).

\section{Clinical Analyses}

Clinical data for these families are summarised in Table 2. Age at onset was between 2 and 10 years in both reference families, BOU-001 and ABD-210. ${ }^{20} \mathrm{~A}$ similar age at onset was observed for family GHA-018, but for families TER-162 and GOU-1021 onset was in the second decade of life. Foot and spine deformities, which were also reported in families BOU-001 and ABD-210, were observed in three or four patients in three new families where the stage of disability ranged from 1 to $4 .^{21}$ The values for MNCV were homogeneous, ranging from 20 to $30 \mathrm{~m} / \mathrm{s}$ in $14 / 16$ patients including those from two of the three new families. The sural nerve biopsy in patient TER-162-004 showed severe loss of axons and of myelinated fibres with signs of Schwann cell proliferation in surviving nerve fibres. Moreover, thickening of the basal lamina from Schwann cells were observed but no onion bulb was observed, as described by Kessali et al. ${ }^{20}$

\section{Mapping of Genes in the 5q31-q33 Contig}

Approximately 40 genes have been identified in the 5q31-q33 region according to the OMIM and GDB databases, but only EGR1 is specifically expressed in Schwann cells or in the peripheral nervous system. The 


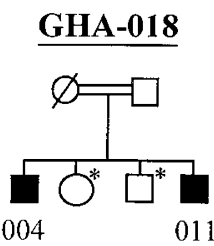

CHII-104

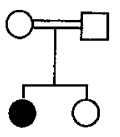

FAR-025

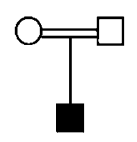

TER-162

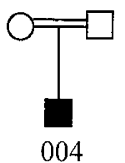

KET-037

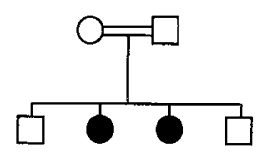

MOU-171

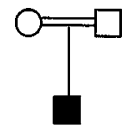

AIT-087

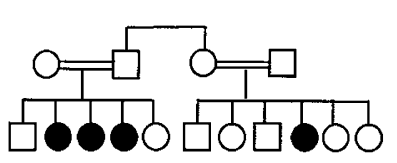

EST-221

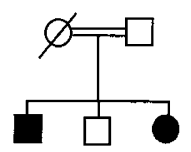

MAN-265<smiles>[CH][CH]O</smiles>

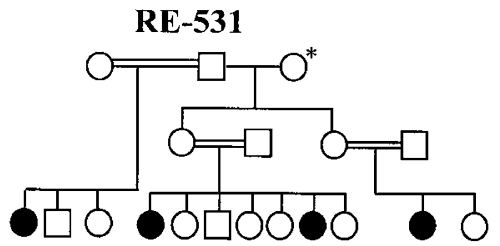

CER-295

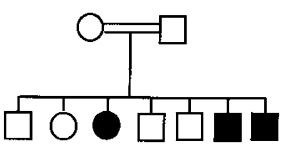

ALS-332

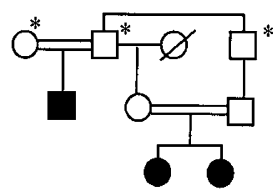

BAS-551

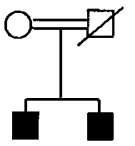

MAK-576

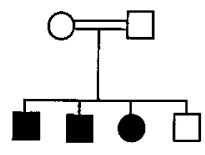

AIT-337
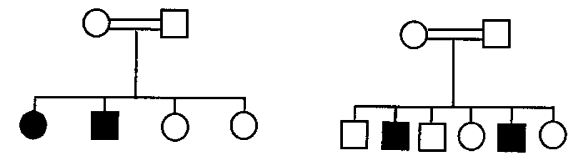

Figure 2 Simplified pedigrees of 17 consanguineous families with demyelinating ARCMT tested for linkage to the 5q31-q33 region. Black symbols represent affected individuals. All individuals were available for study except those indicated by asterisks. The parents are first cousins in all families, except for GHA-018 where they are second cousins. Families with high posterior probability of linkage are underlined. Pedigrees of both Algerian families (BOU-001 and ABD-210), in which linkage was identified with the $5 q$ region, were reported in LeGuern et $\mathrm{al}^{5}$

EGR1 gene could not be amplified, however, by PCR on YACs from the contig, whilst a positive amplification was obtained with total genomic DNA. This supports the proposition that EGR1 is not in the candidate region. Fourteen other candidate genes, selected depending on their function and/or their expression pattern (Table 3 ), were also studied by PCR. Only two were found on the contig. First, $A D R B 2$ (adrenergic $\beta 2$ receptor) was assigned to YACs 746E11, 335D9 and $180 \mathrm{~B} 3$ and thus was located at the telomeric end of the contig outside of the candidate interval, probably between markers D5S686 and D5S434. Second, CDX1 (caudal type homeobox 1) was located on YACs 445F6, 939F12, 812E8, 841D10, 780B9, 951A10 and 930G10, probably between D5S1481 and D5S210 at the telomeric side of the smallest common homozygosity region. The other genes studied $(C A N X, C S F 1 R$, CTNNA1, DBN1, FBN2, FGFA, GM2A, GRL, ITGA2, LMNB1, PDGFRB and SPARC) were not considered further as candidates because of the absence of specific PCR product with the DNA from any of the 23 YACs of the contig. Furthermore, patients from families BOU-001 and ABD-210 were heterozygous for polymorphisms described in FBN2 and $F G F A$ genes, ${ }^{16,17}$ confirming that these genes are not likely to be responsible for this form of CMT.

\section{Sequencing Candidate Genes}

To confirm exclusion of the EGR1 and $C D X 1$ genes, we searched for mutations in their coding sequences. The EGR1 gene could not be amplified by RT-PCR using mRNA extracted from lymphoblastoid cell lines. We therefore determined its exon/intron structure by analogy with the structure of the rat egrl gene. ${ }^{22}$ A single $721 \mathrm{bp}$ intron at nucleotide 577 (reference human cDNA sequence; accession number X52541) was found (Figure 4). The two coding exons and the intron boundaries were sequenced. No base changes were 
Table 1 Two-point lod scores for the haplotype D5S643/D5S436 in 19 consanguineous families with an autosomal recessive form of demyelinating CMT

\begin{tabular}{|c|c|c|c|c|c|c|c|c|c|}
\hline Family & $\theta$ & 0.00 & 0.01 & 0.05 & 0.10 & 0.20 & 0.30 & 0.40 & $\begin{array}{l}\text { Conditional } \\
\text { probability } \\
\text { of linkage }\end{array}$ \\
\hline BOU-001 & & 5.46 & 5.37 & 5.00 & 4.52 & 3.49 & 2.37 & 1.15 & 1.00 \\
\hline$\underline{\mathrm{ABD}-210}$ & & 4.28 & 4.19 & 3.79 & 3.57 & 2.34 & 1.16 & 0.53 & 0.99 \\
\hline GHA-018 & & 1.77 & 1.72 & 1.55 & 1.34 & 0.91 & 0.51 & 0.19 & 0.95 \\
\hline FAR-025 & & -2.60 & -1.26 & -0.61 & -0.35 & -0.14 & -0.05 & -0.01 & 0.08 \\
\hline KET-037 & & 0.00 & 0.00 & 0.00 & 0.00 & 0.00 & 0.00 & 0.00 & $0.25^{\mathrm{a}}$ \\
\hline AIT-087 & & $-\infty$ & -4.88 & -2.29 & -1.26 & -0.44 & -0.16 & -0.02 & 0.00 \\
\hline CHI-104 & & -1.50 & -1.02 & -0.51 & -0.29 & -0.11 & -0.04 & -0.01 & 0.01 \\
\hline TER-162 & & 0.79 & 0.77 & 0.68 & 0.58 & 0.38 & 0.21 & 0.08 & 0.67 \\
\hline MOU-171 & & -2.69 & -1.13 & -0.49 & -0.26 & -0.09 & -0.03 & -0.01 & 0.07 \\
\hline EST-221 & & $-\infty$ & -1.71 & -0.91 & -0.55 & -0.23 & -0.09 & -0.02 & 0.00 \\
\hline MAN-265 & & -2.69 & -1.13 & -0.49 & -0.26 & -0.09 & -0.03 & -0.01 & 0.00 \\
\hline CER-295 & & $-\infty$ & -5.32 & -2.66 & -1.62 & -0.71 & -0.28 & -0.07 & 0.00 \\
\hline ALS-332 & & $-\infty$ & -3.93 & -1.94 & -1.15 & -0.48 & -0.18 & -0.04 & 0.00 \\
\hline SAI-336 & & -2.39 & -1.14 & -0.51 & -0.27 & -0.11 & -0.05 & -0.03 & 0.00 \\
\hline AIT-337 & & -3.04 & -1.75 & -0.98 & -0.62 & -0.28 & -0.12 & -0.03 & 0.00 \\
\hline RE-531 & & $-\infty$ & -7.00 & -4.20 & -3.20 & -1.05 & -0.36 & -0.09 & 0.00 \\
\hline BAS-551 & & $-\infty$ & -0.98 & 0.76 & 1.27 & 1.34 & 0.96 & 0.37 & 0.00 \\
\hline MAK-576 & & $-\infty$ & -4.15 & -2.14 & -1.31 & -0.58 & -0.24 & -0.07 & 0.00 \\
\hline GOU-1021 & & 1.00 & 0.97 & 0.87 & 0.75 & 0.50 & 0.29 & 0.12 & 0.76 \\
\hline
\end{tabular}

Lod scores were calculated with a haplotype frequencies ranging from 0.02 to 0.05 , depending on the frequency of the transmitted alleles at each loci. Conditional probability was calculated using the HOMOG program. ${ }^{13}$ Family SAL-KET-037 was uninformative for both markers D5S643 and D5S436.

observed in patients compared with controls. The three exons and corresponding intron boundaries of the $C D X 1$ gene were sequenced in eight individuals from families BOU-001 and ABD-210, but no mutations were identified compared to the reference sequence. ${ }^{19}$

\section{Discussion}

Homozygosity mapping in two large Algerian families with consanguinity assigned a locus responsible for an autosomal recessive demyelinating form of CMT to $5 \mathrm{q} 23-\mathrm{q} 33 .{ }^{5}$ In order to identify genes that might be responsible for this ARCMT, we constructed a physical map of the candidate region focused on the smallest homozygosity region observed in family BOU-001. ${ }^{5}$ Nine YACs from a previously established contig of the 5q31-q33 region ${ }^{7}$ and 14 new YACs from the CEPH permitted each interval in the candidate region to be covered by three to eight YACs, some of which are non- chimeric. Localisation of 10 additional microsatellite markers in this contig permitted ordering of some of the microsatellites and definition of the smallest region of homozygosity to a $<2 \mathrm{Mb}$ interval between markers $116 \mathrm{YC5}$ and D5S210, which is the most probable location of the gene. Combined FISH and Alu-PRINS banding refined the locus cytogenetically to band $5 \mathrm{q} 32$.

Linkage analysis of 17 consanguineous families with demyelinating CMT identified three new families with a high posterior probability of linkage to the ARCMT locus on chromosome 5q. This locus accounts, therefore, for a significant proportion (about 20\%) of demyelinating ARCMT families in Europe and North Africa. A recent study of Dutch families with ARCMT localised the gene in a $7 \mathrm{cM}$ region between D5S643 and D5S670. ${ }^{23}$ There are some discrepancies between their genetic data and the new marker order defined by the present study. However, the only consanguineous family from their study is homozygous for a region between D5S402 and D5S410, a marker localised 7 cM 


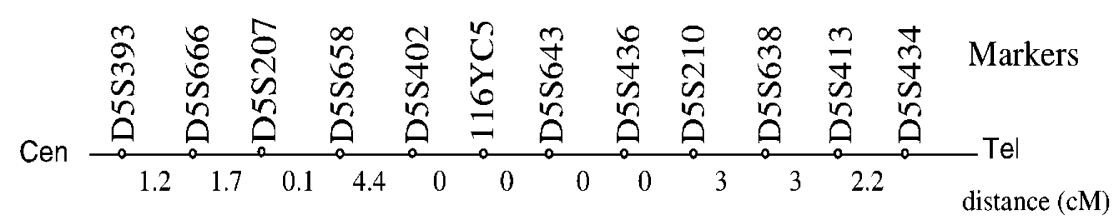

Family $\underline{\text { Patient }}$
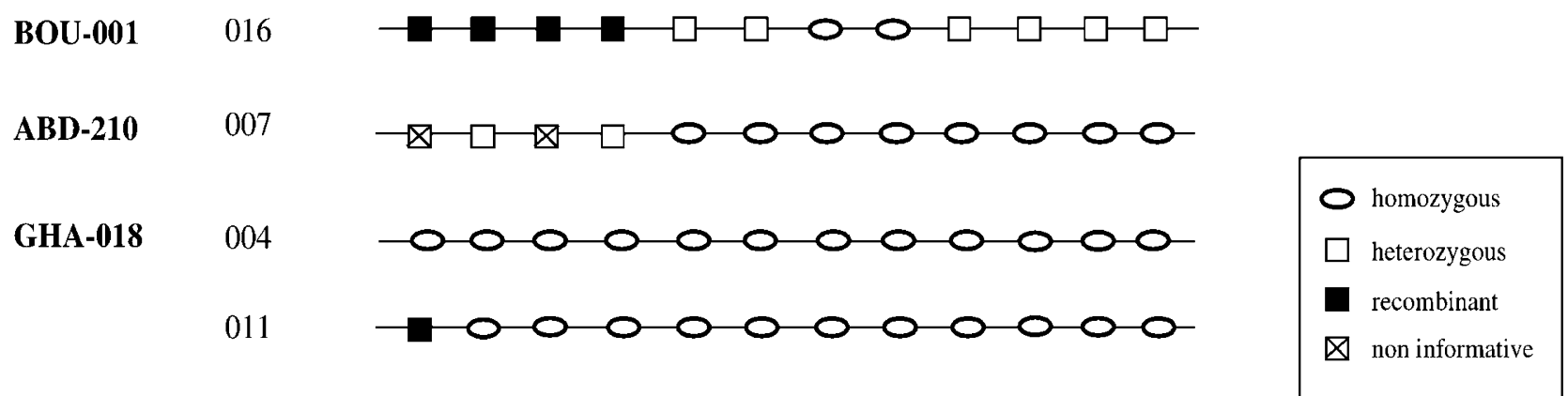

TER-162 004

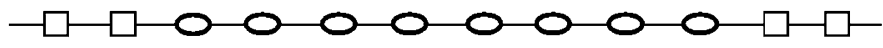

GOU-1021 001

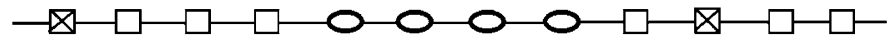

Figure 3 Region of homozygosity and recombination events in patients with probable linkage to chromosome $5 q$. For families BOU001 and $A B D-210$, only the most informative patient is represented. Patients are identified in Figure 2. The homozygosity regions observed for each patient overlap and include markers D5S643 and D5S436

telomeric to D5S434. This region overlaps the homozygosity region observed in our families. Haplotyping in our three families with 12 chromosome 5 markers did not reduce the homozygosity region detected in family BOU-001 but confirms the order of microsatellites determined by physical mapping. No common allele of any marker segregated with the disease in the five families. Given their geographical origins (Algeria, Morocco, Tunisia and France), there is no reason to suspect a common ancestral mutation. Clinical examination showed an interfamilial variability of the phenotype which could be explained by the effect of different mutations. Kessali $e t a l^{20}$ have already noted a large intrafamilial variability concerning the course of the disease. Although foot and spine deformities were observed in 15 of 16 patients, they were not necessarily associated with a severe stage of disability. This discrepancy between the rapid worsening of deformities and the relatively slow evolution of the motor deficit has already been reported by Kessali et al. ${ }^{20}$ Nerve biopsy in patient TER-162-004, for whom MNCV was not recordable because of absent evoked response, confirmed the demyelinating nature of the disease. Two differences were observed on nerve biopsies among patients from families ABD-210 and
TER-162. First, the axonal loss observed in patient TER-162-004 is more severe than in family ABD- $210^{20}$ and second, no onion bulbs were found in TER162-004. However, thickenings of basal lamina from Schwann cells in TER-162-004 are very similar to the several concentric layers of basal lamina surrounding myelinated fibres described by Kessali et al. ${ }^{20}$ The basal lamina defect, which seems to be very specific for this form of demyelinating CMT, could constitute a useful morphological criteria for characterising this disease. Unfortunately, neuropathological examinations were missing in two of the new families.

Recently, mutations in zinc finger domains of the EGR2 gene (also known as Krox-20) were associated with congenital hypomyelination $(\mathrm{CHN})$ and CMT1. ${ }^{24}$ $E G R 1$, like EGR2, is an immediate early serum response gene. Both encode closely related zinc finger phosphoproteins that act as transcription factors. ${ }^{25}$ According to their expression pattern in mouse, Krox20 (egr 2 ) and Krox-24 (egr1) would play antagonistic roles during the development of the Schwann cell lineage. Krox-24 appears to repress the myelination or to induce the non-myelinating state. ${ }^{25}$ Although EGRI represented an evident candidate gene because of its location in 5q21-q33, it maps outside of the candidate 


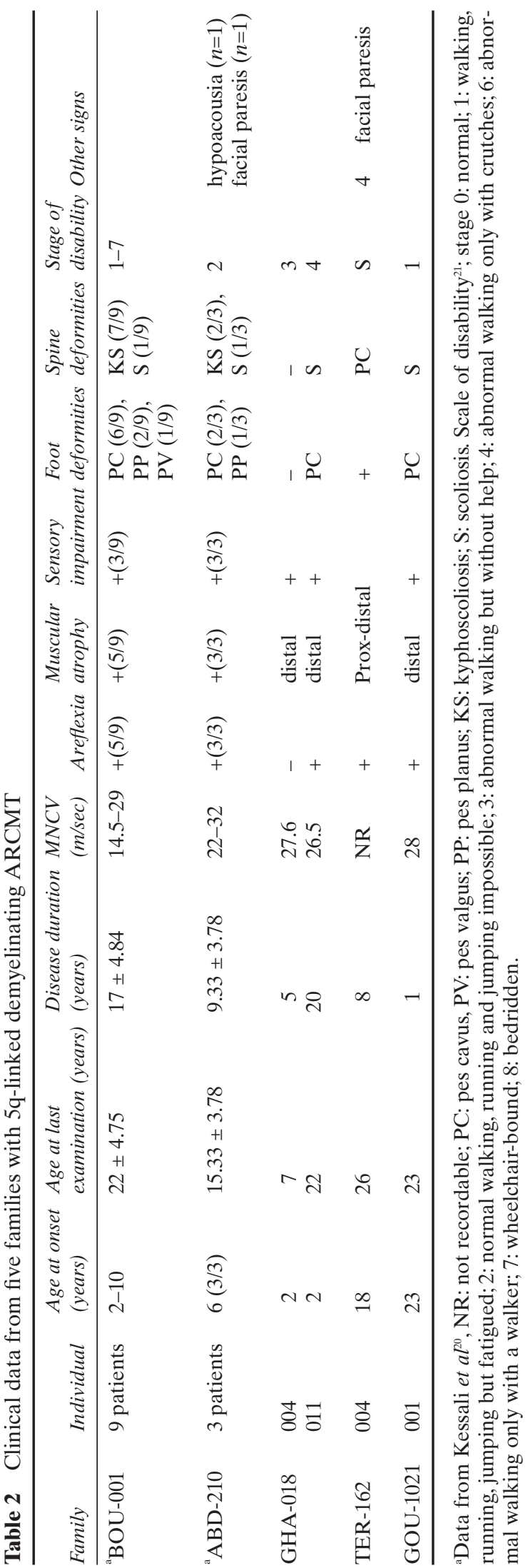


Table 3 PCR primers and conditions for mapping of the candidates genes

\begin{tabular}{|c|c|c|c|c|}
\hline Genes $^{\text {ref }}$ & & Primer pairs & $\begin{array}{l}\text { Amplification } \\
\text { product size (bp) }\end{array}$ & $\begin{array}{l}\text { Annealing } \\
\text { temperature }\end{array}$ \\
\hline$A D R B 2^{28}$ & adrenergic B2 receptor & $\begin{array}{l}\text { GTACTGTGCCTAGCGATAAC } \\
\text { TATAGCAGACTCAGGTCCTC }\end{array}$ & 345 & $60^{\circ} \mathrm{C}$ \\
\hline$C A N X^{29}$ & calnexin & $\begin{array}{l}\text { ATGGAAGGGAAGTGGTTG } \\
\text { GGAGATGAAGGAGGAGCA }\end{array}$ & 167 & $50^{\circ} \mathrm{C}$ \\
\hline$C D X 1^{26}$ & caudal type homeobox 1 & $\begin{array}{l}\text { GTAAGACTCGGACCAAGG } \\
\text { CCGGATTGTGATGTAACGGCT }\end{array}$ & 131 & $60^{\circ} \mathrm{C}$ \\
\hline$C S F 1 R^{30}$ & $\begin{array}{l}\text { colony stimulating factor- } 1 \\
\text { receptor }\end{array}$ & $\begin{array}{l}\text { TCATCACTTCCAGAATGTGC } \\
\text { TGTGTCCAGCCTTAGTGTGCA }\end{array}$ & 117 & $55^{\circ} \mathrm{C}$ \\
\hline$C T N N A 1^{31}$ & catenin alpha-1 & $\begin{array}{l}\text { GTTGAGAGACTGTTGGAG } \\
\text { CCCTTTACTATTGGTGTT }\end{array}$ & 66 & $57^{\circ} \mathrm{C}$ \\
\hline$D B N 1^{32}$ & drebrin $\mathrm{E}$ & $\begin{array}{l}\text { CTGAGGGAGAAAGGG } \\
\text { TTACGAGGAGGTGAT }\end{array}$ & 127 & $50^{\circ} \mathrm{C}$ \\
\hline$E G R 1^{18,33}$ & early growth response 1 & $\begin{array}{l}\text { GCACGCTTCTCAGTGTTCCC } \\
\text { CGTTGCTCAGCAGCATCATC }\end{array}$ & 260 & $58^{\circ} \mathrm{C}$ \\
\hline$F B N 2^{16}$ & fibrillin 2 & $\begin{array}{l}\text { AAGGTGTTCTTTGCATGTTCACC } \\
\text { GTAATGTGTTCTATCTAGTTCAACG }\end{array}$ & $110-115$ & $55^{\circ} \mathrm{C}$ \\
\hline$F G F A^{17}$ & fibroblast growth factor A & $\begin{array}{l}\text { CTCAGAGCTGCAGTAGCCT } \\
\text { GTAGCATTACATTTGCACTTGG }\end{array}$ & $245-259$ & $55^{\circ} \mathrm{C}$ \\
\hline$G M 2 A^{34}$ & GM2 activator & $\begin{array}{l}\text { GACCTCTGCCGCCTC } \\
\text { CACCTCCTTCTCCAA }\end{array}$ & 323 & $50^{\circ} \mathrm{C}$ \\
\hline$G R L^{35}$ & glucocorticoid receptor & $\begin{array}{l}\text { TCACGAGGGCTTGTAGTAGGT } \\
\text { AGTCACGGCACCCAGCCAAT }\end{array}$ & 700 & $60^{\circ} \mathrm{C}$ \\
\hline$I T G A 2^{36}$ & integrin alpha 2 & $\begin{array}{l}\text { CGCTCAGTCAAGGCATTT } \\
\text { CCATTCGGTTCTCAGGAA }\end{array}$ & 180 & $60^{\circ} \mathrm{C}$ \\
\hline$L M N B 1^{37}$ & lamin B1 & $\begin{array}{l}\text { GGGTGGGCAGTCCCA } \\
\text { CCACTCACACACGCA }\end{array}$ & 399 & $58^{\circ} \mathrm{C}$ \\
\hline$P D G F R B^{38}$ & $\begin{array}{l}\text { platelet derived growth factor } \\
\text { receptor }\end{array}$ & $\begin{array}{l}\text { TCATGCTTTGGCAGAAGGTA } \\
\text { ATAGCTCGGGCCAGGCTCAG }\end{array}$ & 220 & $57^{\circ} \mathrm{C}$ \\
\hline$S P A R C^{39}$ & osteonectin & $\begin{array}{l}\text { GATCTAAATCCACTCCTTCC } \\
\text { CAGATCCGTGTCCACCCATG }\end{array}$ & 270 & $58^{\circ} \mathrm{C}$ \\
\hline
\end{tabular}

region and no base changes were detected by analysis of its whole coding sequence in selected patients, probably excluding coding region point mutation as responsible for the disease. Two other genes, $A D R B 2$ and $C D X 1$, located in the contig were also excluded. $A D R B 2$ was mapped in its telomeric end, outside the homozygosity region. In contrast, $C D X 1$ was considered as a candidate gene because of its location on YACs overlapping the homozygosity region. This location is in contradiction with a previous study placing it telomeric to $A D R B 2 .^{26}$ The disruption of the murine homeobox gene $C D X 1$ leads to axial skeletal deformities with anterior homeotic transformation. ${ }^{27}$ As most patients with this form of CMT present severe anterior spine deformities, this gene was considered as a good candidate both by its position and its function. How- ever, direct sequencing of $C D X 1$ coding sequence in CMT patients failed to identify any mutation. The availability of the YAC contig and the refinement of the homozygosity region to a less than $2 \mathrm{Mb}$ interval should greatly help to identify and test new candidate genes or ESTs in the region. Identification of the gene responsible for this demyelinating neuropathy would help to understand the pathogenesis of this and other autosomal recessive myelinopathies.

\section{Acknowledgements}

We are grateful to the members of the CMT research group, especially Professor M Salih and Dr R Gouider who referred 
A

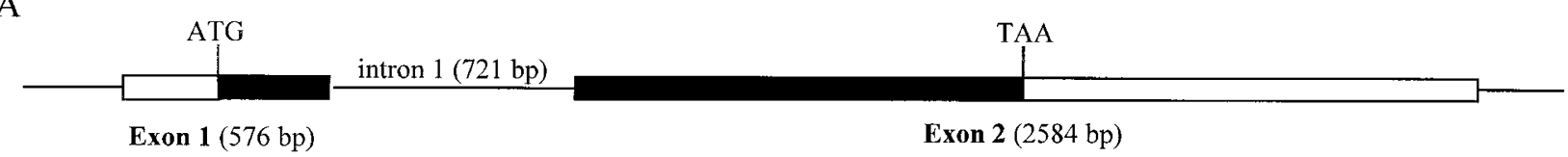

$\mathrm{B}$

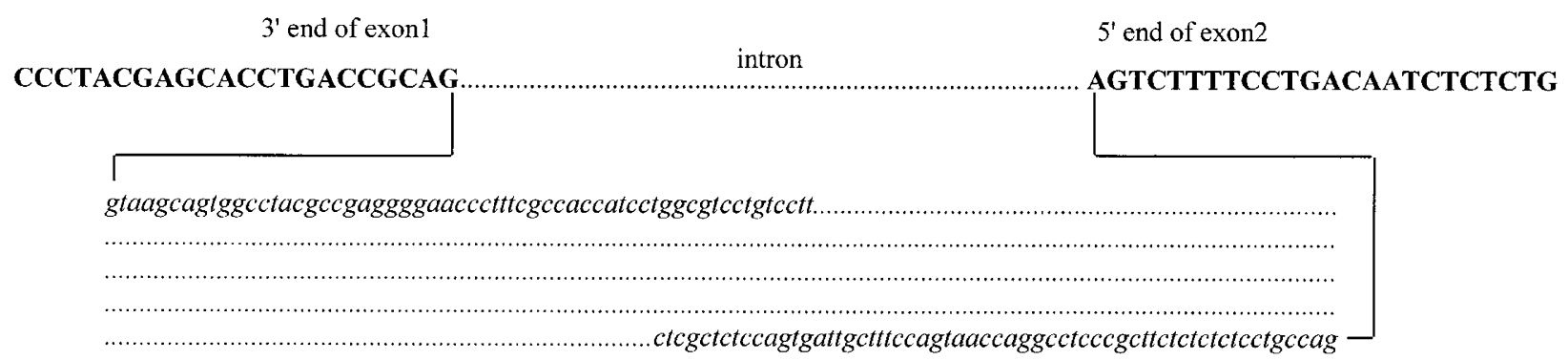

Figure 4 A schematic representation of the human EGR1 gene. The black boxes represent the open reading frame for exon 1 and 2 , the sizes of which are 306 and 1325 bp respectively. ${ }^{33}$ B $A$ single intron was identified and the nucleotide sequences of exon/intron boundaries are indicated. The coding sequences are shown in bold capitals and the intron in lower case italics

several families. We thank M Ruberg for critical reading of the manuscript, and G Scarpelli, P Gesnouin and C Hascoet, all at Infobiogen (Villejuif, France) for their help with the linkage calculations. This work was supported by grants from the Association Française contre les Myopathies. The authors AG, NB, DG, AB and EL are members of the European CMT consortium sponsored by the Union Biomed 2 grant (CT 961614 and CT 960055). We especially thank the families for their participation in this study. Finally, we are also grateful to the Assistance Publique des Hôpitaux de Paris and the Association pour le Développement de la Recherche sur les Maladies Neurologiques et Psychiatriques.

\section{References}

1 Ben Othmane K, Hentati F, Lennon F et al: Linkage of a locus (CMT4A) for autosomal recessive Charcot-MarieTooth disease to chromosome 8q. Hum Mol Genet 1993; 2: 1625-1628.

2 Dyck PJ, Thomas PK: Peripheral Neuropathy. WB Saunders: Philadelphia, 1993.

3 Othmane KB, Loeb D, Hayworth-Hodgte R et al: Physical and genetic mapping of the CMT4A locus and exclusion of PMP-2 as the defect in CMT4A. Genomics 1995; 28: 286-290.

4 Bolino A, Brancolini V, Bono F et al: Localization of a gene responsible for autosomal recessive demyelinating neuropathy with focally folded myelin sheaths to chromosome 11q23 by homozygosity mapping and haplotype sharing. Hum Mol Genet 1996; 5: 1051-1054.
5 LeGuern E, Guilbot A, Kessali M et al: Homozygosity mapping of an autosomal recessive form of demyelinating Charcot-Marie-Tooth disease to chromosome 5q23-q33. Hum Mol Genet 1996; 5: 1685-1688.

6 Kalaydjieva L, Hallmayer J, Chandler D et al: Gene mapping in Gypsies identifies a novel demyelinating neuropathy on chromosome 8q24. Nat Genet 1996; 14: 214-217.

$7 \mathrm{Li} \mathrm{X}$, Wise CA, Le Paslier D et al: A YAC contig of approximately $3 \mathrm{Mb}$ from human chromosome 5q31-> q33. Genomics 1994; 19: 470-477.

8 Chumakov IM, Rigault P, Le Gall I et al: A YAC contig map of the human genome. Nature 1995; 377: 175-297.

9 Dib C, Faure S, Fizames C et al: A comprehensive genetic map of the human genome based on 5,264 microsatellites. Nature 1996; 380: 152-154.

10 Pellestor F, Girardet A, Lefort G, Andreo B, Charlieu JP: Use of the primed in situ labelling (PRINS) technique for a rapid detection of chromosomes $13,16,18,21, \mathrm{X}$ and $\mathrm{Y}$. Hum Genet 1995; 95: 12-17.

11 Goguel AF, Pulcini F, Danglot G, Fauvet D, Devignes MD, Bernheim A: Mapping of 22 YACs on human chromosomes by fish using yeast DNA $A l u$-PCR products for competition. Ann Genet 1996; 39: 64-68.

12 Cole CG, Goodfellow PN, Bobrow M, Bentley DR: Generation of novel sequence tagged sites (STSs) from discrete chromosomal regions using Alu-PCR. Genomics 1991; 10: 816-826.

13 Ott J: Analysis of Human Genetic Linkage. John Hopkins University Press: Baltimore, 1991.

14 Lathrop GM, Lalouel JM, Julier C, Ott J: Multilocus linkage analysis in humans: detection of linkage and estimation of recombination. Am J Hum Genet 1985; 37: 482-498. 
15 Schaffer AA, Gupta SK, Shriram K, Cottingham RW Jr: Avoiding recomputation in linkage analysis. Hum Hered 1994; 44: 225-237.

16 Biddinger AL, Hecht JT, Milewicz DM: Repeat polymorphisms in human fibrillin genes on chromosome 15 (FBN1) and chromosome 5 (FBN2). Hum Mol Genet 1993; 2: 1323-1323.

17 Li X, Jaye M, Crumley G, Jabs EW: Dinucleotide repeat polymorphism in the human fibroblast growth factor acidic (FGFA) gene on chromosome 5. Hum Mol Genet 1992; 1: 216-216.

18 Sukhatme VP, Cao XM, Chang LC et al: A zinc fingerencoding gene coregulated with $c$-fos during growth and differentiation, and after cellular depolarization. Cell 1988; 53: 37-43.

19 Mallo GV, Rechreche H, Frigerio JM et al: Molecular cloning, sequencing and expression of the mRNA encoding human $C d x 1$ and $C d x 2$ homeobox. Down-regulation of $C d x 1$ and $C d x 2$ mRNA expression during colorectal carcinogenesis. Int J Cancer 1997; 74: 35-44.

20 Kessali M, Zemmouri R, Guilbot A et al: A clinical, electrophysiologic, neuropathologic, and genetic study of two large Algerian families with an autosomal recessive demyelinating form of Charcot-Marie-Tooth disease. Neurology 1997; 48: 867-873.

21 Birouk N, Gouider R, LeGuern E et al: CMT1A with 17p11.2 duplication: clinical and electrophysiological phenotype study and factors of disorders severity in 119 cases. Brain 1997; 120: 813-823.

22 Changelian PS, Feng P, King TC, Milbrandt J: Structure of the NGFI-A gene and detection of upstream sequences responsible for its transcriptional induction by nerve growth factor. Proc Natl Acad Sci USA 1989; 86: 377-381.

23 Gabreëls-Festen A, van Beersum S, Eshuis L et al: Study on the gene and phenotypic characterisation of autosomal recessive demyelinating motor and sensory neuropathy (Charcot-Marie-Tooth disease) with a gene locus on chromosome 5q23-q33. J Neurol Neurosurg Psychiatry 1999; 66: 569-574.

24 Warner LE, Mancias P, Butler IJ et al: Mutations in the early growth response 2 (EGR2) gene are associated with hereditary myelinopathies. Nat Genet 1998; 18: 382-384.

25 Topilko P, Levi G, Merlo G et al: Differential regulation of the zinc finger genes Krox-20 and Krox-24 (Egr-1) suggests antagonistic roles in Schwann cells. $J$ Neurosci Res 1997; 50: 702-712.

26 Bonner CA, Loftus SK, Wasmuth JJ: Isolation, characterization, and precise physical localization of human $C D X 1$, a caudal-type homeobox gene. Genomics 1995; 28: 206-211.
27 Subramanian V, Meyer BI, Gruss P: Disruption of the murine homeobox gene $C d x 1$ affects axial skeletal identities by altering the mesodermal expression domains of Hox genes. Cell 1995; 83: 641-653.

28 Jabs EW, Li X, Lovett $\mathrm{M}$ et al: Genetic and physical mapping of the Treacher Collins syndrome locus with respect to loci in the chromosome $5 \mathrm{q} 3$ region. Genomics 1993; 18: 7-13.

29 Tjoelker LW, Seyfried CE, Eddy RLJ et al: Human, mouse, and rat calnexin cDNA cloning: identification of potential calcium binding motifs and gene localization to human chromosome 5. Biochemistry 1994; 33: 3229-3236.

30 Polymeropoulos $\mathrm{MH}$, Xiao H, Rath DS, Merril CR: Dinucleotide repeat polymorphism at the human $c$-fms protooncogene for the CFS-1 receptor (CFS1R). Nucleic Acids Res 1991; 19: 1160-1160.

31 Rimm DL, Kebriaei P, Morrow JS: Molecular cloning reveals alternative splice forms of human alpha(E)catenin. Biochem Biophys Res Commun 1994; 203: 1691-1699.

32 Toda M, Shirao T, Minoshima S, Shimizu N, Toya S, Uyemura K: Molecular cloning of cDNA encoding human drebrin E and chromosomal mapping of its gene. Biochem Biophys Res Commun 1993; 196: 468-472.

33 Suggs SV, Katzowitz JL, Tsai-Morris C, Sukhatme VP: cDNA sequence of the human cellular early growth response gene Egr-1. Nucleic Acids Res 1990; 18: 4283.

34 Xie B, Kennedy JL, McInnes B, Auger D, Mahuran D: Identification of a processed pseudogene related to the functional gene encoding the GM2 activator protein: localization of the pseudogene to human chromosome 3 and the functional gene to human chromosome 5. Genomics 1992; 14: 796-798.

35 Hollenberg SM, Weinberger C, Ong ES et al: Primary structure and expression of a functional human glucocorticoid receptor cDNA. Nature 1985; 318: 635-641.

36 Takada Y, Hemler ME: The primary structure of the VLA2/collagen receptor alpha 2 subunit (platelet GPIa): homology to other integrins and the presence of a possible collagen-binding domain. J Cell Biol 1989; 109: 397-407.

37 Lin F, Worman HJ: Structural organization of the human gene $(L M N B 1)$ encoding nuclear lamin B1. Genomics 1995; 27: 230-236.

38 Gronwald RG, Grant FJ, Haldeman BA et al: Cloning and expression of a cDNA coding for the human plateletderived growth factor receptor: evidence for more than one receptor class. Proc Natl Acad Sci USA 1988; 85: $3435-3439$.

39 Warrington JA, Hall LV, Hinton LM, Miller JN, Wasmuth JJ, Lovett M: Radiation hybrid map of 13 loci on the long arm of chromosome 5. Genomics 1991; 11: 701-708. 